\title{
Sand Slurry Erosive Wear Behavior of Hot Extruded Al6061-SiC Composites
}

\author{
C.S. Ramesh*, R. Keshavamurthy \\ Department of Mechanical Engineering, PES Institute of Technology, 100ft Ring Road, BSK III \\ Stage, Bangalore-560 085. \\ Corresponding Author: csr_gce@yahoo.co.in
}

\begin{abstract}
Aluminum based composites are very popular in automotive and aerospace segments. In particular aluminum alloy-SiC composite systems are widely studied and seriously explored for various other applications in defense and space. However they have not been looked at as potential materials in naval and chemical applications where synergistic effects of both wear and corrosion need to be addressed to. This needs the assessment of wear behavior of composites. From the survey, it is evident that major focus is on mechanical and corrosion properties of cast composites. However, meager information is available as regards the slurry erosive wear behavior of cast and extruded metal matrix composites.

In the light of the above, the present investigation is aimed at studying in detail the slurry erosive wear behavior of cast and hot extruded Al6061 and Al6061-SiC composites in sand slurry. Al6061-SiC composites have been prepared primarily by vortex method. Hot extrusion of these composites and the matrix alloy has been carried out at $550^{\circ} \mathrm{C}$ using a $500 \mathrm{~T}$ hydraulic press. Both as cast and hot extruded composites have been subjected to microstructure studies, microhardness, and slurry erosive wear tests. The hot extruded composites exhibit higher hardness, and slurry erosive wear resistance when compared with as cast alloy and its composites.
\end{abstract}

Keywords: Slurry erosive wear, Hot extrusion, Composites, Silicon carbide.

\section{INTRODUCTION}

Aluminum alloys have excellent mechanical properties coupled with good corrosion resistance. However, they possess poor wear resistance. To improve the above said property, researchers 
have successfully dispersed various hard and soft reinforcements such as $\mathrm{SiC}, \mathrm{Al}_{2} \mathrm{O}_{3}$, glass, graphite, mica, and coconut shell char in aluminum alloys by different processing routes [1-3]. In recent years, considerable interest has been shown in extending the use of metal matrix composites in the marine environment [4]. This demands evaluation of corrosion as well as erosion-corrosion characteristics of the composite materials under simulated marine environment.

A few studies have been reported by different investigators on erosive -corrosive wear behavior of $\mathrm{Al}$ alloy and its composites [5]. Erosion-corrosion of MMCs takes place usually by three different mechanisms (i) corrosion of the matrix alloy (ii) abrasion /erosion of the matrix as reinforcements by the impact of suspended erodent. The corrosion of the matrix takes place by an oxidation reaction [6] when $\mathrm{Al}^{3+}$ is released from the matrix to the slurry. This results in exposure of large fresh area of the specimen surface to the slurry which causes further removal of matrix alloy leading to higher material loss in the initial stages.

As time progresses, the slurry adjacent to the specimen surface gets saturated with $\mathrm{Al}^{3+}$, resulting in a reduction in $\mathrm{pH}$ of slurry. As a result, the dissolution rate of $\mathrm{Al}^{3+}$ in the slurry is reduced and the excess $\mathrm{Al} 3+$ is deposited over the specimen surface which combines with $\mathrm{OH}^{-}$to form $\mathrm{Al}(\mathrm{OH})_{3}$ compound over the specimen surface. This passive layer so long as it is not broken, protects the matrix from direct contact with the slurry and slows down the rate of weight loss. Additionally [7-8] the gas evolved during corrosion is entrapped into the crater micro sites (formed due to coming out of particulates or removal of matrix) and protects these sites from the slurry which further slows down the rate of weight loss.

It is reported that characteristics of aluminum metal matrix composites have been improved by subjecting the cast composites to hot extrusion as studied and reported by Alkpas et.al [2], Straffelini et.al [9], Joshi[10], and Ganesh et.al [11]. Hot Extrusion has considerably improved the microstructure and the mechanical of stir cast Al-Si-Pb alloys and greatly decreased the porosity. At room temperature the hot extruded Al-Si-Pb alloys have demonstrated better wear resistance than base alloys as reported by An et.al [12].

Contrary to these findings, some other investigators [13-14] have reported reduced wear rates of the composites where the matrix alloy contained hard particles such as $\mathrm{SiC}, \mathrm{Al}_{2} \mathrm{O}_{3}, \mathrm{SiO}_{2}, \mathrm{Si}_{3} \mathrm{~N}_{4}$ and glass. Of all the techniques available for preparing the composite, the liquid metallurgy route is the most popular one as reported by Ramesh et.al [15]. However, the composites produced by this route will have inherent casting defects thereby limiting the practical applications of composites. To overcome this, it is very much essential to adopt the secondary forming process on cast composites in particular hot extrusion. From the literature survey it is quite evident that most of the researchers have focused their attention on friction and wear behavior of primarily processed composites. However meager literature is available as regards the tribological 
properties of secondary processed metal matrix composites In the light of the above, this paper discusses the effect of hot extrusion of Al6061-SiC on its hardness and erosive wear properties.

\section{EXPERIMENTAL DETAILS}

\subsection{Composite Preparation and Hot Extrusion}

A batch of 3.5kgs of Aluminum 6061 alloy was melted using a 6KW electric furnace. The melt was degassed using commercially available chlorine based tablets (Hexachloroethane). The molten metal was agitated by use of mechanical stirrer rotating at a speed of $300 \mathrm{rpm}$ to create a fine vortex. Preheated $\mathrm{SiC}$ (preheated to $700^{\circ} \mathrm{C}$ for $2 \mathrm{hrs}$ ) were added slowly in to the vortex while continuing the stirring process. The stirring duration was $10 \mathrm{~min}$. The composites melt maintained at a temperature of $710^{\circ} \mathrm{C}$ was then poured in to preheated metallic moulds. The stirrer blades used were made of stainless steel and were coated with ceramic material to minimize the iron pickup by the molten metal. The amount of SiC was varied from 4 to $8 \mathrm{wt} \%$ in steps of 2. The cast matrix alloy and its composites were hot extruded at a temperature of $550^{\circ} \mathrm{C}$ with an extrusion ratio of 9.0 using a 500T hydraulic press at National Physical Laboratory, New Delhi, India. Microstructural studies, hardness, and erosive wear tests were conducted on both the cast and extruded matrix alloy and composites. Hardness of all the studied materials were evaluated at $50 \mathrm{~g}$ for a duration of 10 seconds using micro hardness tester.

\subsection{Fabrication Details of Erosion Test Set Up}

Erosion test set up fabricated is shown in Fig.1. This machine consists of a motor with a speed control unit having the specification of a mixer grinder with a maximum speed of $8000 \mathrm{rpm}$. The slurry mixture is filled in the stainless steel jar. The jar has a provision for holding the specimen along with it. The specimen holder assembly details are shown in Fig 2. The specimen is cylindrical having $8 \mathrm{~mm}$ diameter and $15 \mathrm{~mm}$ height. The specimen is held in the specimen holder at an inclination of $0^{\circ}$ as per the ASME standards.

\section{RESULTS AND DISCUSSIONS}

\subsection{Microstructure}

The microstructure of cast and extruded matrix alloy Al6061 and its composites are shown in Fig.3. The microstructures clearly indicate the homogeneity in the distribution of reinforcements in the matrix alloy. Further, it is evident that the particles have got damaged during the extrusion process in addition to being oriented along the extrusion direction. 


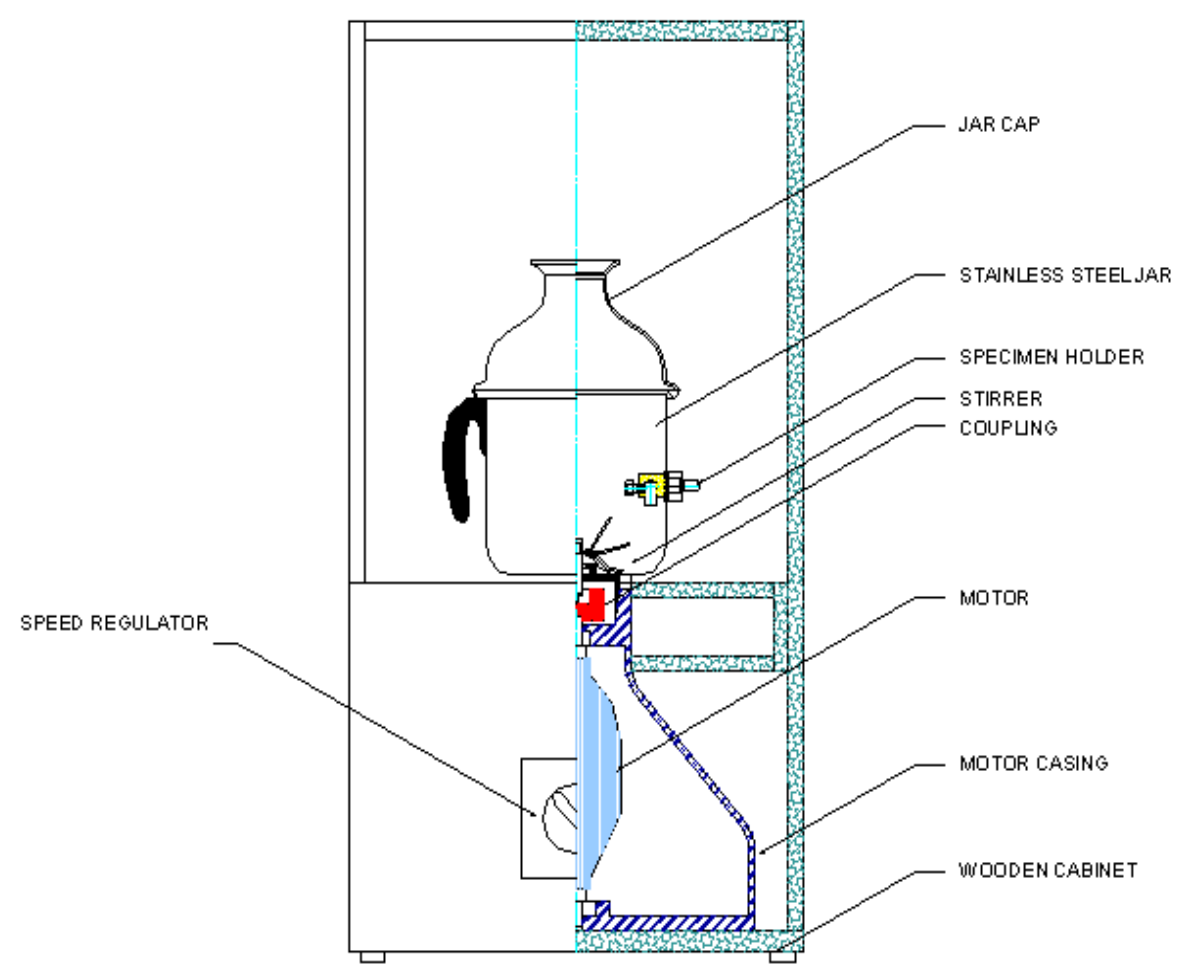

Fig. 1. Erosion testing set up

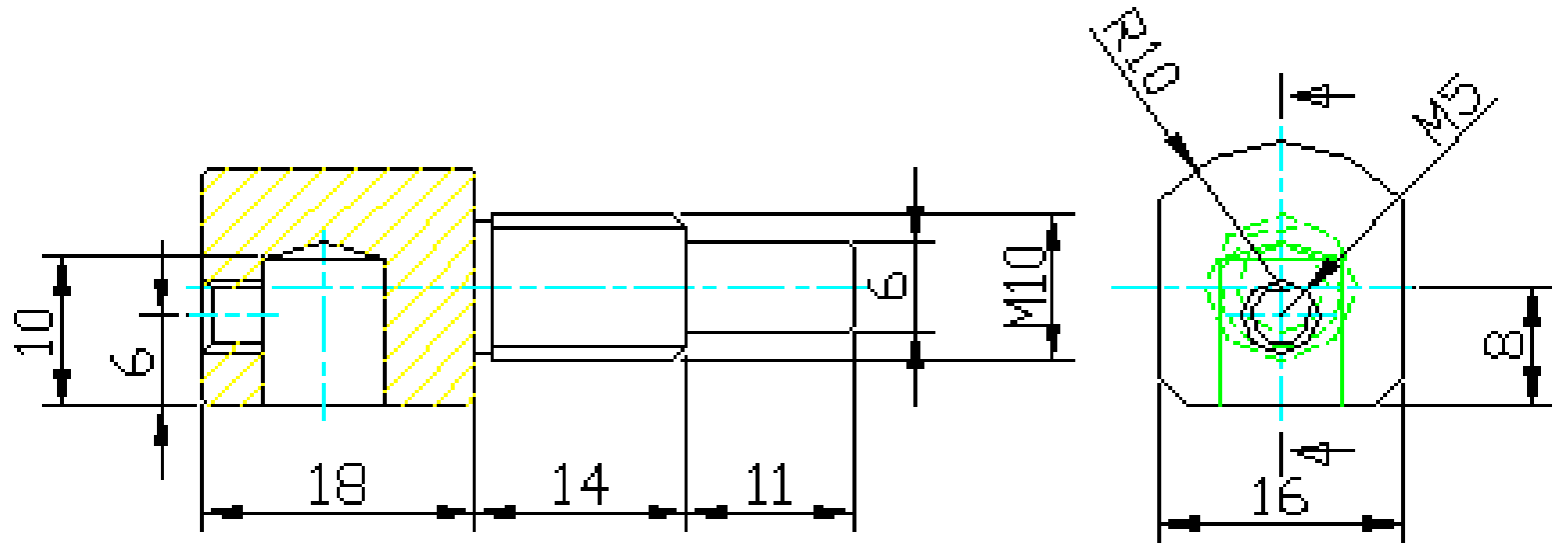

Fig. 2. Specimen holder drawing 


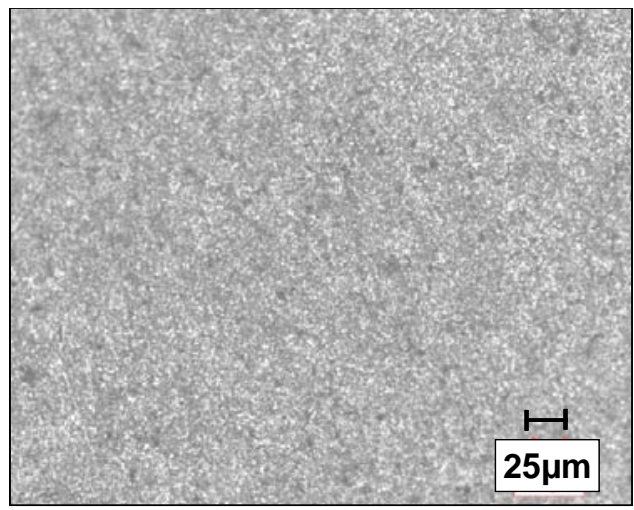

(a) Cast Al6061 alloy

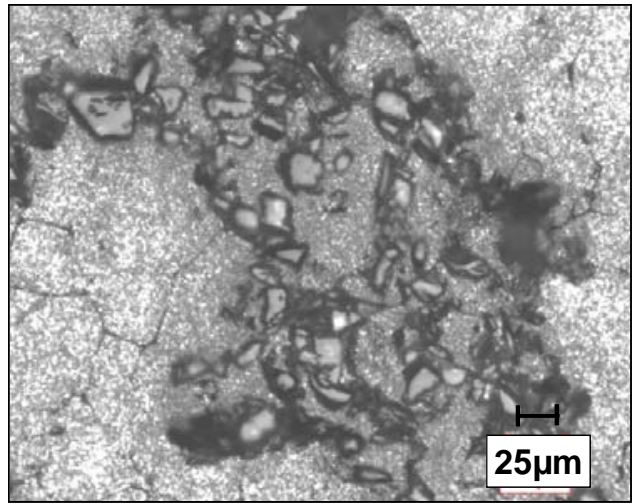

(c)Cast Al6061-8wt \% SiC composite

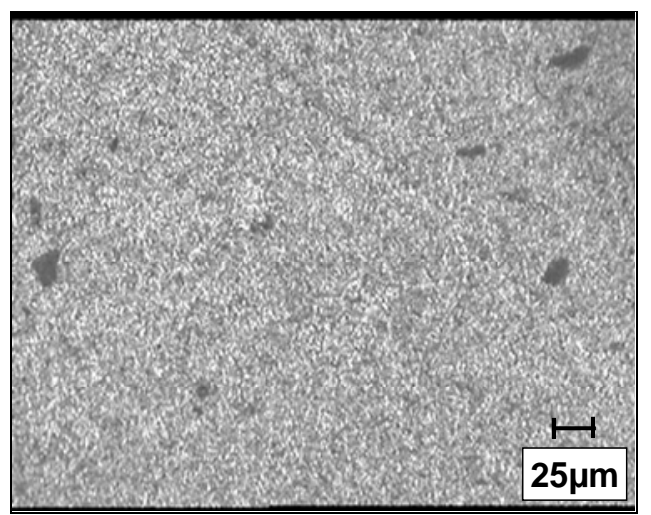

(b) Extruded Al6061 alloy

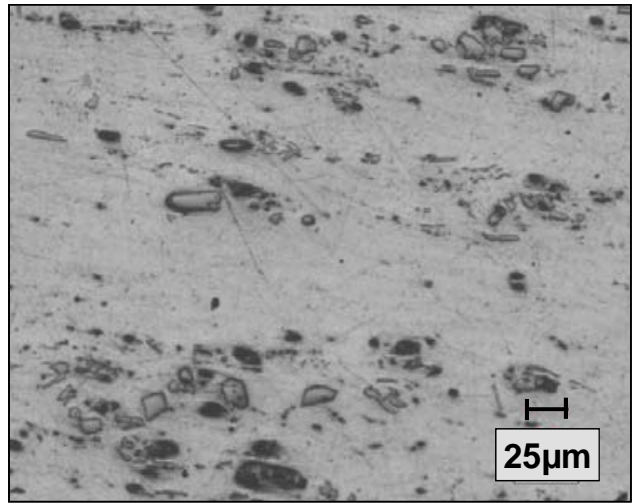

(d) Extruded Al6061-8wt\%SiC composite

Fig. 3. Microphotographs of cast and extruded Al6061 and its composites

\subsection{Microhardness}

The variation of hardness of composites with increased contents of reinforcement is shown in Fig.4. It is observed that increased content of the reinforcement results in enhanced hardness of the composites. This can be attributed to the fact that SiC is a hard ceramic. Addition of hard phase to a soft ductile matrix leads to improved hardness as reported by Ramesh and Seshadri [16]. However; the extruded composites exhibit a higher hardness when compared with cast composites. This can be attributed to healing up of casting defects during extrusion. For the matrix alloy, an increase in hardness of $12 \%$ is observed and for cast Al6061-8wt\% SiC an increase in hardness of $36 \%$ is noticed on hot extrusion.

\subsection{Slurry Erosive Wear Results}

\subsubsection{Effect of percentage weight of reinforcement:}

There is a significant reduction in the slurry erosive wear rate of the composites with an increase in the percentage weight of the reinforcement as shown in the Fig 5 . This can be attributed to the 
higher hardness of the composite as discussed earlier higher the hardness better is the erosive wear resistance of the materials.

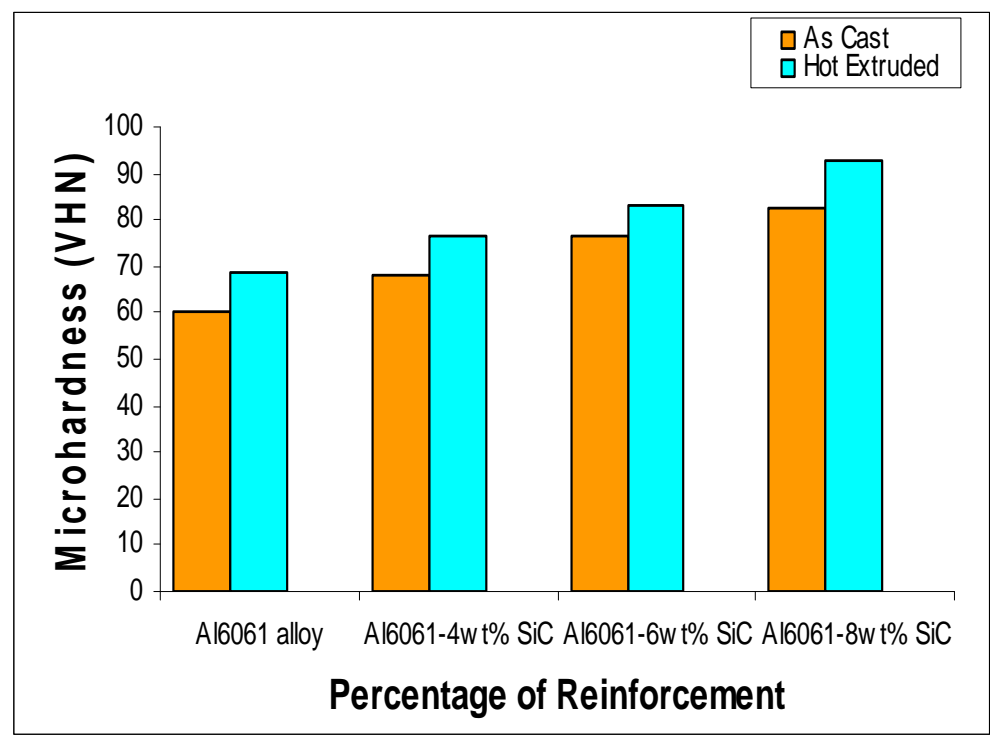

Fig. 4. Variation of microhardness of cast and extruded Al6061 alloy and Al6061-SiC composites.

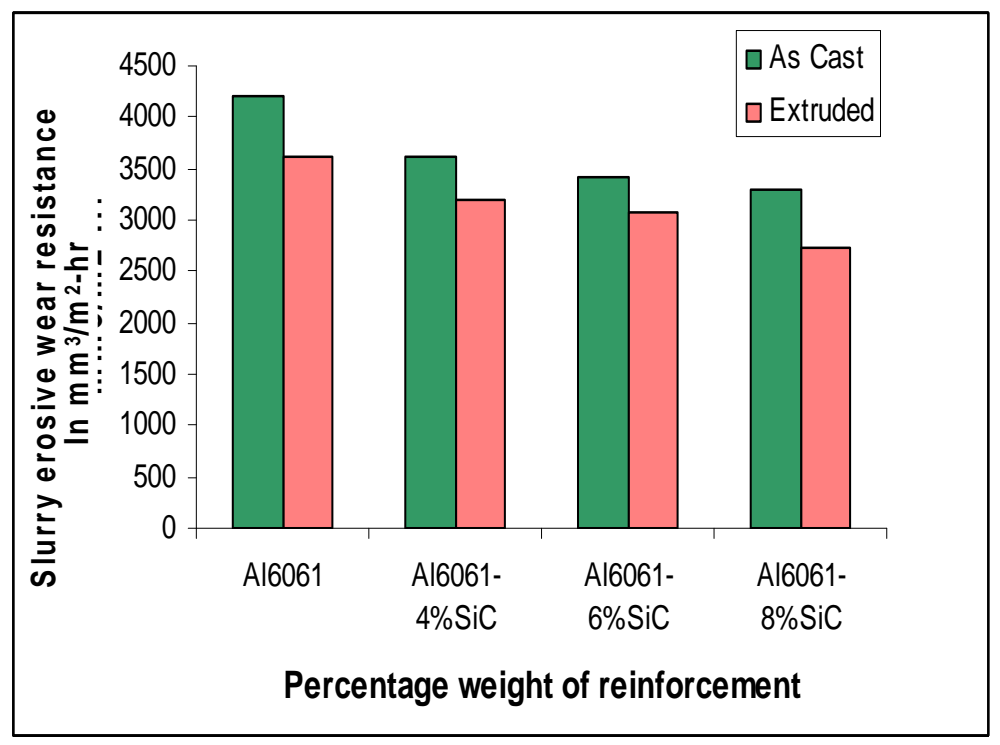

Fig. 5. Variation of Slurry erosive wear rate of cast and hot extruded Al6061 alloy and Al6061-SiC composites. 


\subsubsection{Effect of slurry concentration}

The slurry erosive wear rates of base Al6061 alloy and Al6061-SiC composites with different concentration of silica slurry at a given slurry rotation and time duration is as shown in Fig. 6. It is observed that increased slurry concentration results in higher slurry erosive wear rate of both the base alloy and its composites studied. Increased slurry erosive wear rates at higher slurry concentrations can be attributed to the fact that increased abrasive particle concentration in the slurry will enhance the probability of larger impingement surface in the slurry. This in turn will result in increased deterioration of the material from its surface.

This phenomenon is clearly observed on subjecting the worn surfaces to SEM studies. Increased slurry concentration has resulted in higher density of cracking and also certain deposit formations over the exposed surface as shown in Fig.7. However, increased content of reinforcement in the matrix alloy reduces the slurry erosive wear rate for all the slurry concentrations studied. This can be attributed to the higher hardness of composites with increased content of $\mathrm{SiC}$ particles in the matrix alloy. It is also clear that extrusion have a significant effect on slurry erosive wear resistance of both the matrix alloy and all the composite systems studied.

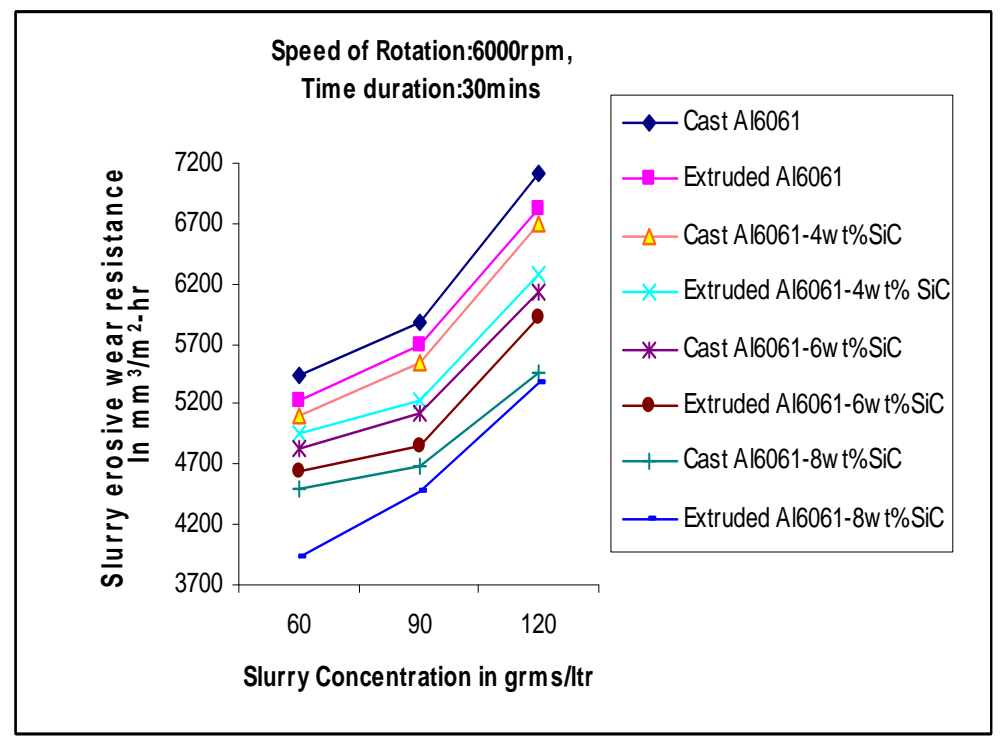

Fig. 6. Variation of Slurry erosive wear rate of cast \& hot extruded Al6061 alloy and Al6061-SiC composites for different slurry concentrations. 


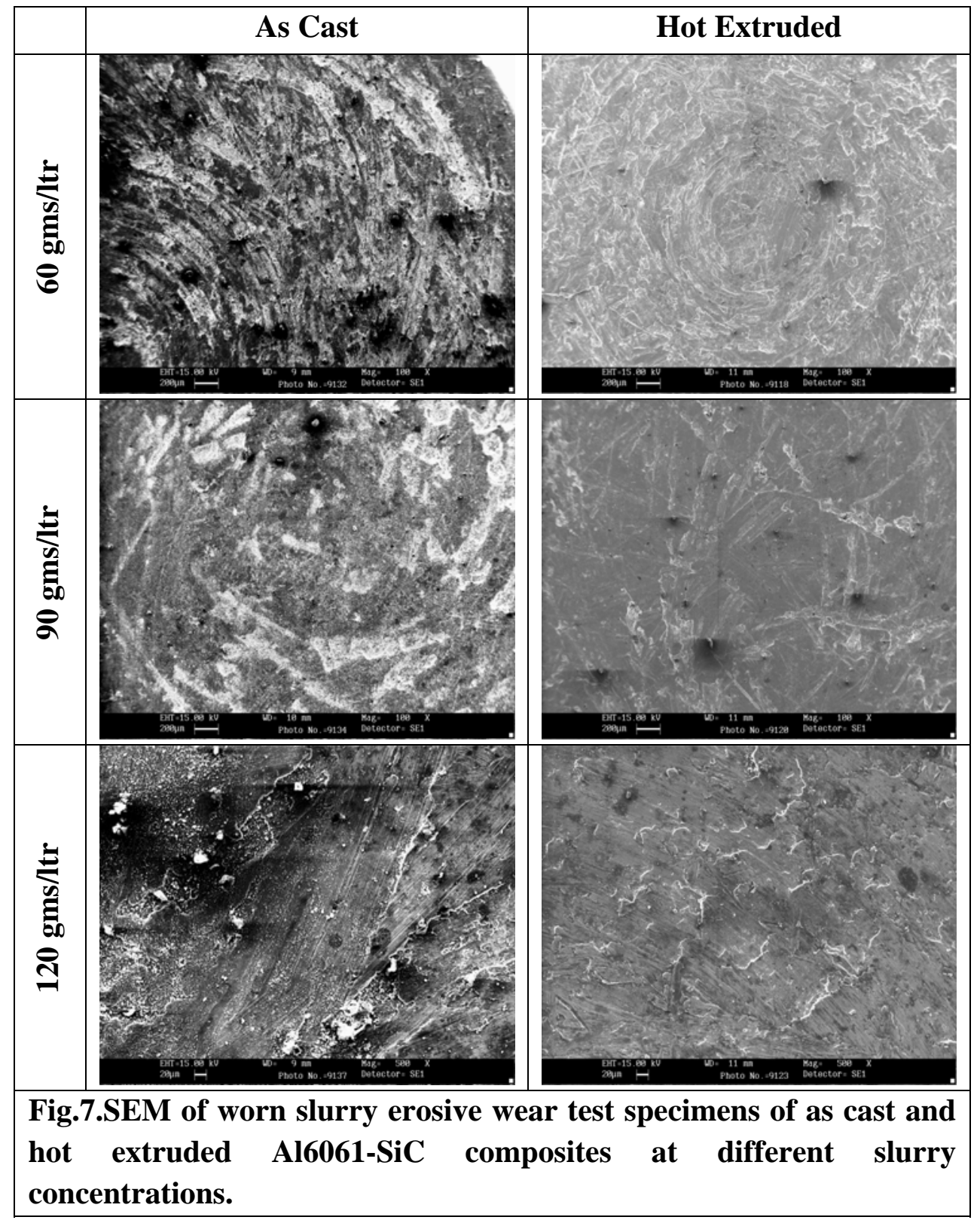

\subsubsection{Effect of speed of slurry rotation}

The slurry erosive wear rate of Al6061 alloy and Al6061-SiC composites with different speed of silica slurry rotation at constant time duration and slurry concentration is as shown in Fig. 8. It is observed that increased speed of slurry rotation results in higher slurry erosive wear rate of both cast and extruded base alloy and its composites studied. At very high speed of $8000 \mathrm{rpm}$ 
maximum slurry erosive wear rate is observed. The increased speed of the slurry rotation will tend to increase the velocity of impingement of the abrasive grains present in the slurry. Increased impingement velocity will lead to higher rates of material removal from the surfaces resulting in higher slurry erosive wear rate. The larger extent of impingement at higher speed of slurry rotation is demonstrated by SEM photographs as shown in Fig. 9. These SEM photographs clearly indicate the presence of several craters on the worn surfaces. Higher the speed of slurry rotation larger is the extent of crater formation noticed on the worn. However, increased content of reinforcement in the matrix alloy reduces the slurry erosive wear rate for all the speeds of slurry rotations studied in both cast and extruded conditions. This can be attributed to the higher hardness of composites with increased content of SiC particles in the matrix alloy. It is also clear that extrusion have profound effect on slurry erosive wear resistance of both the matrix alloy and all the composite systems studied. This can be attributed to the fact that extruded specimens possess higher hardness when compared to the cast ones as discussed earlier.

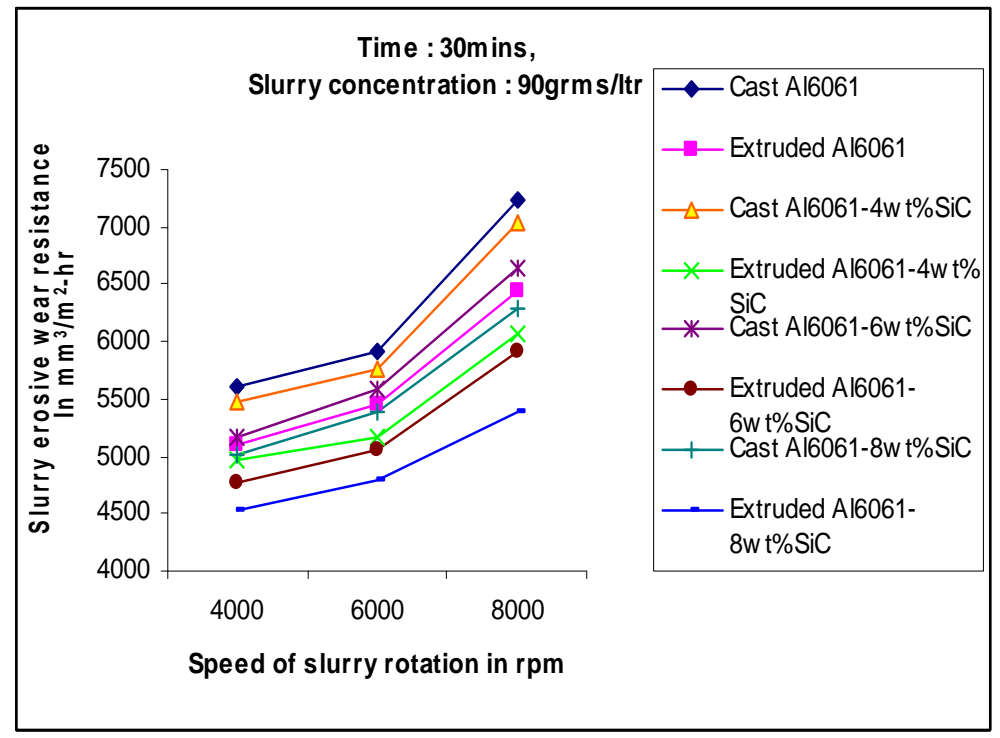

Fig.8. Variation of Slurry erosive wear rate of cast and extruded Al6061 and Al6061-SiC composites for different speed of slurry rotation.

\subsubsection{Effect of time duration}

The slurry erosive wear rates of cast \& extruded Al 6061-SiC composites with different time duration at a given slurry rotation and speed is as shown in Fig. 10. It is observed that increased time duration results in reduction of slurry erosive wear rate for both the base alloy and the composites. This can be attributed to the fact that the surface of the specimen gets strain hardened with as the abrasive particles frequently impinge over its surface. This phenomenon will lower the material loss from the surfaces. Further decrease in weight loss can also be due to 
formation of passive layer over the exposed surface of the specimens which retards the slurry erosive wear rate by acting as a protective layer [17]. However, increased content of SiC in cast and extruded matrix alloy reduces the wear rate for all time duration. This can be attributed to the higher hardness of composites with increased content of $\mathrm{SiC}$ in matrix alloy. Probable deposits are observed in the present study as shown in SEM photographs in Fig. 11. SiC in matrix alloy. Probable deposits are observed in the present study as shown in SEM photographs.

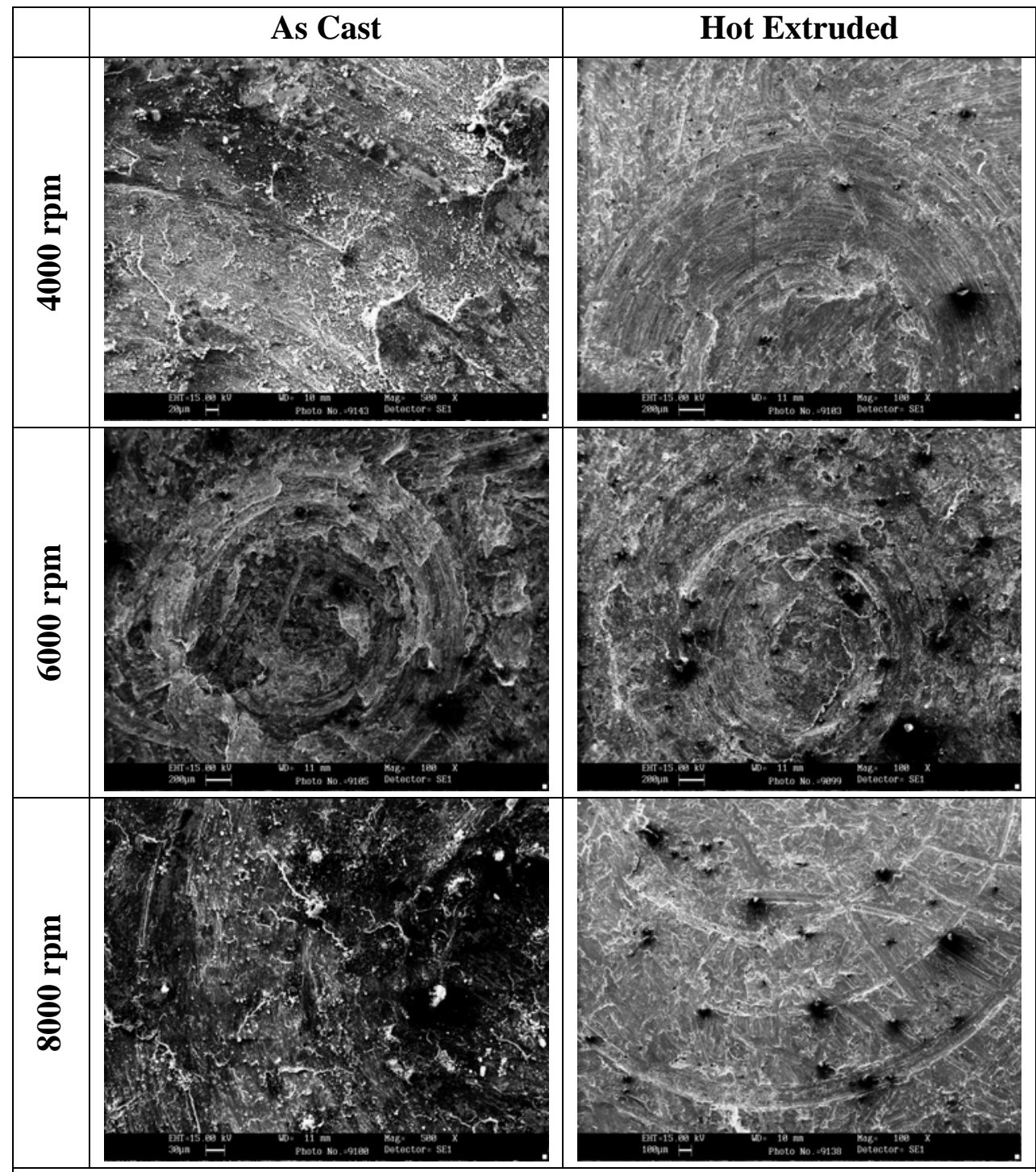

Fig.9.SEM photographs of worn slurry erosive wear test specimens of as cast and hot extruded Al6061-SiC composites at different speed of slurry rotation. 


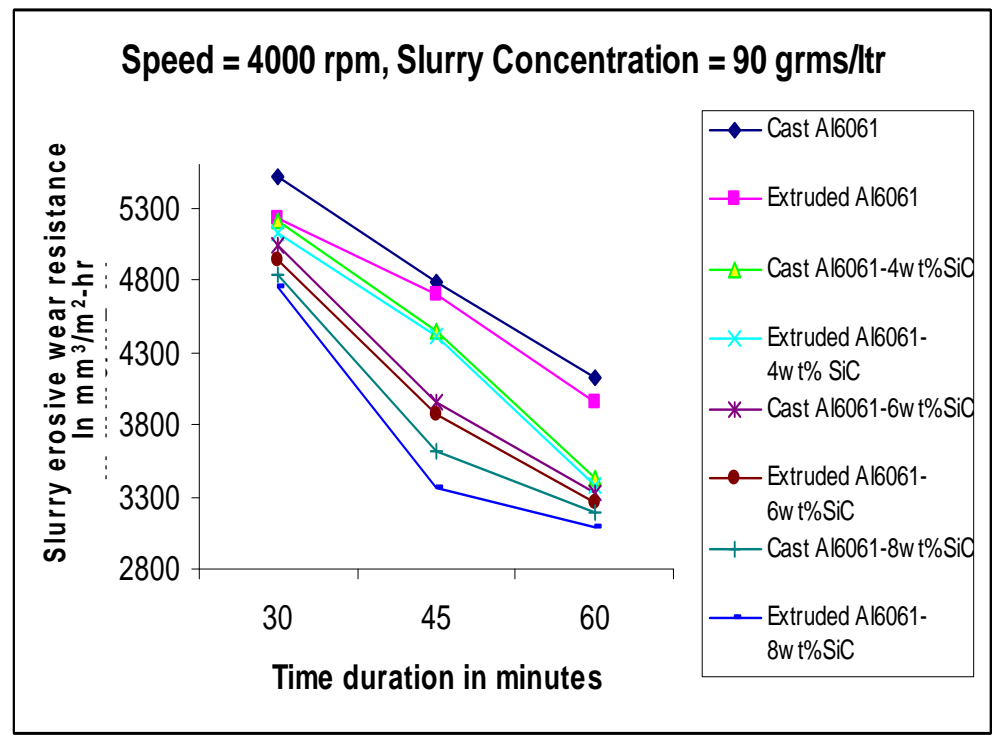

Fig.10. Variation of Slurry erosive wear rate of cast \& extruded composites for different test durations.

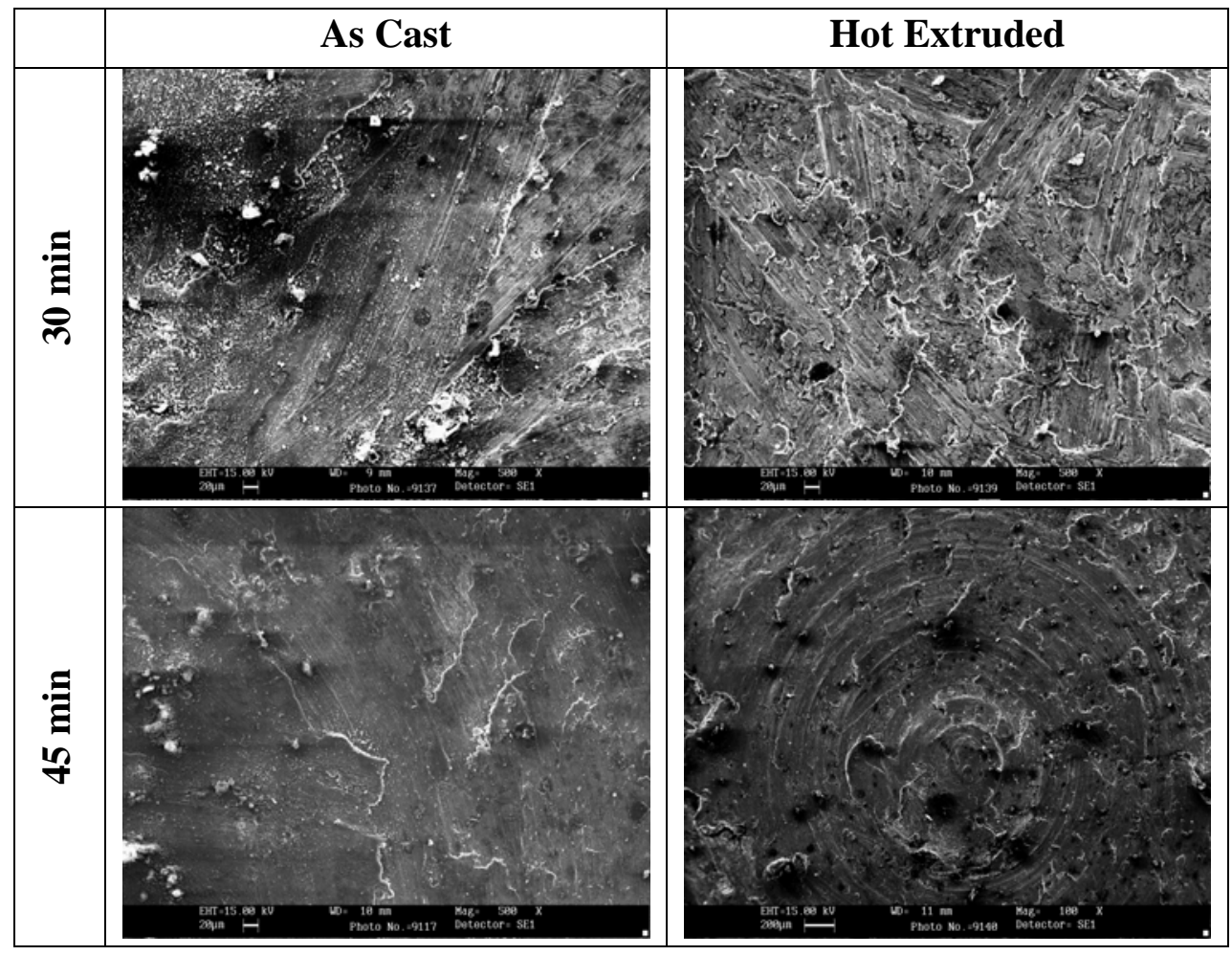




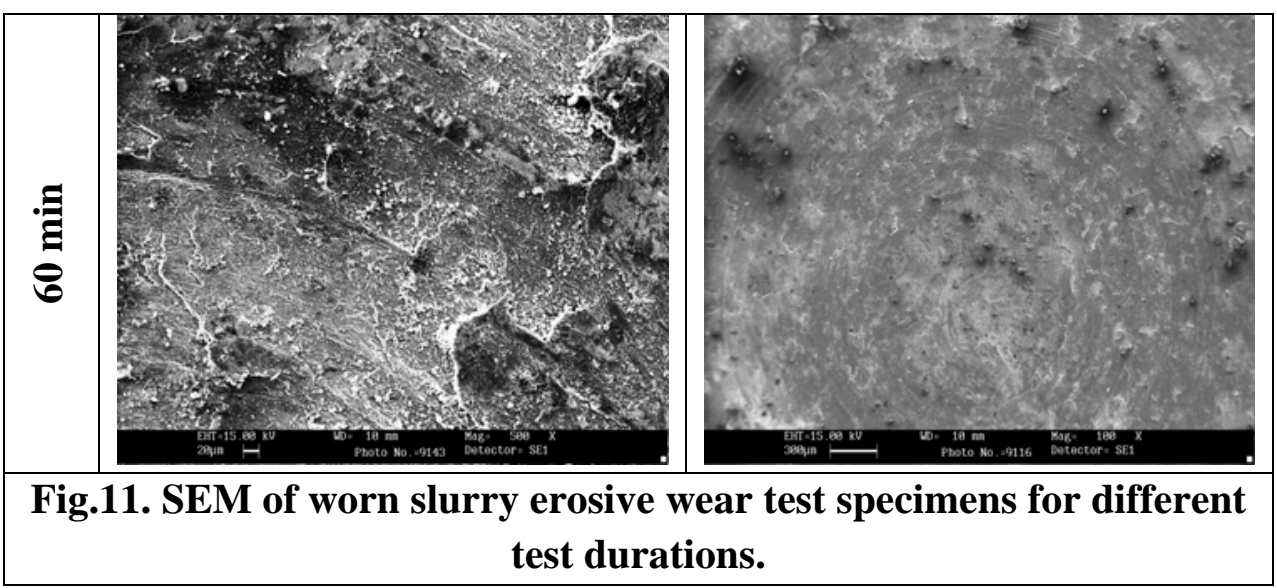

\section{CONCLUSIONS}

Al6061-SiC composites have been successfully prepared by liquid metallurgy route. Up to 8wt\%SiC has been successfully dispersed in the matrix alloy. Cast Al6061 and Al6061-SiC have been successfully hot extruded.

There is a significant increase in slurry erosive wear rate of cast \& extruded base alloy and its composites with an increase in speed of slurry rotation. However, extruded Al6061-SiC composites exhibited better slurry erosive wear resistance when compared with Al6061 alloy and cast Al6061-SiC composites under identical test conditions.

With an increase in test duration, there is a reduction of slurry erosive wear rates of both cast and extruded base alloy and its composites. However, extruded Al6061-SiC composite possesses higher slurry erosive wear resistance when compared with the base alloy and cast Al6061-SiC composites.

\section{REFERENCES}

[1]. Y Sahin , M . Acilar, "Production and properties of SiCp- reinforced aluminium alloy" Composites, Part A 34 (2003) 709-718.

[2]. A.T.Alpas, J.Zhang, "Effect of microstructure and counter face material on sliding wear resistance of particulate reinforced aluminum matrix composites”, Metallurgical \& Materials Transaction, 25 A, (1994) 969-983.

[3]. B. K. Prasad, K. Venkateshwaralu, O.P. Modi, S Das, A. K. Jha, R. Dasgupta, "Effects of $\mathrm{SiC}$ dispersion on the sliding wear characteristics of an $\mathrm{Al}-\mathrm{Cu}$ alloy" Proceedings of the International Conference on Aluminium, INCAL'98, New Delhi, 1998, pp. 9-16.

[4]. S. Das, D.P. Mondal, R. Dasgupta, B.K. Prasad, "Mechanism of material removal during erosion-corrosion of an Al-SiC Particle Composite” Wear 236 (1999) 295-302. 
[5]. M. Saxena, O.P. Modi, B.K. Prasad, A.K. Jha, "Erosion and corrosion characteristics of an aluminium alloy-alumina fibre composite” Wear 169 (1993) 119.

[6]. H.H. Strehblow, International Congress on Metallic Corrosion, June1984, National Research Council, Canada, 1984, pp-99.

[7]. S. Turenne, D. Simard, "Influence of structural parameters on the slurry erosion resistance of squeeze-cast metal matrix composites” Wear 149 (1991) 187-197.

[8]. S. Turenne, Y. Chatigny, D. Simard, S. Caron, J.Masounave, "The effect of abrasive particle size on the slurry erosion resistance of particulate-reinforced aluminum alloy" Wear 141 (1990) 147.

[9]. G.Straffelini, F.Bollo, A.Tiziani, A.Molinari, "Influence of matrix hardness on the dry sliding behaviour of 20vol\% $\mathrm{Al}_{2} \mathrm{O}_{3}$ - particulate reinforced 6061-Al metal matrix composites” Wear 221 (1997) 192-197.

[10]. S.S.Joshi , N Ramakrishnan, P. Ramakrishnan, "Hot extrusion of Al/SiCp composites" Proceedings of Third International Conference on Advances in Composites", ADCOMP V2 (2000) 911.

[11]. V.Ganesh, C.K.Lee, M.Gupta, "Enhancing the tensile modulus and strength of Aluminuim alloy Interconnected reinforcement methodology", Materials Science \& Engg. A 333 (2002) 193-198.

[12]. J.An, Y..B.Liu, Y.Liu, Q.Y.Zhang, C.Dong, "Dry sliding wear behaviour of hot extruded Al-Si-Pb alloys in the temperature range 25-200 ${ }^{\circ} \mathrm{C}$ ”, Wear 256, (2004), 374-385.

[13]. A. Sato and R. Mehrabian, "Formation of Spinel $\left(\mathrm{MgAl}_{2} \mathrm{O}_{4}\right) \mathrm{MgO}$ and pure $\mathrm{Cu}$ Particles in Al-Zn-Mg alloy-CuO particles composites”, Metallurgical Trans, 7B (1976) 443.

[14]. L.Cao, Y. Wang, C.K Yao, "The wear properties of a Sic-whisker-reinforced aluminum composite” Wear, 24 (1990) 273.

[15]. C.S.Ramesh, A.R.Anwar Khan, N.Ravikumar, P.Savan Prabhu, "Prediction of wear coefficient of Al6061- $\mathrm{TiO}_{2}$ Composites” Wear, (2005), 602-608.

[16]. C.S.Ramesh, S K Seshadri, "Tribological characteristics of Nickel composite coatings" Wear 225 (2003) 893-902.

[17]. Ramachandra. M, Radhakrishna. K, "Sliding wear, Slurry erosive wear and corrosion wear behavior of Aluminium / $\mathrm{SiC}_{\mathrm{p}}$ composite" Material science-Poland Vol.24.No.2/1.2006. 